\title{
Measurements and Factors of Carbon Emission Efficiency
}

\author{
Lili Chen, Feng He* \\ Donlinks School of Economics and Management, University of Science and Technology Beijing, \\ Beijing, 100083, P.R. China
}

Received: 21 February 2017

Accepted: 28 March 2017

\begin{abstract}
A shortage of natural resources is currently handicapping further socio-economic development in China. The Chinese government has therefore implemented several measures to limit energy use and reduce harmful emissions, with a particular focus on the provinces. We calculated and compared the regional carbon emission efficiency of China from 2006 to 2013 using the Charnes-Cooper-Rhodes, Banker-Charnes-Cooper, slackbased measurement models and the epsilon-based measure of efficiency model. In addition, we compared our results with those of other local and overseas scholars. The 30 provinces of China were divided into eight economic regions and we analyzed the differences in carbon emission efficiency of these regions. Finally, we used the DEA-Tobit model to study the relationship between economic scale, industrial structure, environmental regulation, dependence on foreign trade and foreign capital, technological innovation, and carbon emission efficiency. Our main conclusions include: 1) the efficiency value calculated by EBM was more reasonable compared with that of the other models, 2) significant differences were found in the carbon emission efficiency between the regions, and 3) economic scale, industrial structure, dependence on foreign trade and foreign capital, and technological innovation were the positive factors. Furthermore, environmental regulation was found to have no significant effect on carbon emission efficiency, whereas regional characteristics had negative effects.
\end{abstract}

Keywords: carbon emission efficiency, DEA, provincial, environmental regulation, undesirable output

\section{Introduction}

Since 1978, unprecedented socio-economic development has led to the annual growth rate of China increasing by $15.73 \%$ from 1979 to 2013 , and the country becoming the second largest economy in the world [1-3]. Scientists posit that climate change is causing environmental degradation and natural disasters,

*e-mail: hefeng@manage.ustb.edu.cn threatening human health and safety. However, the scaledriven economic development model is based on utilizing a large number of natural resource [4-5], which has caused a shortage of such resources in the country. In view of the new round of industrialization and urbanization during the $12^{\text {th }}$ Five-Year Plan (2011-15), this shortage has become a crucial constraint on the economic growth and social development of China [6].

World energy demand continues to grow alongside global economic and social development. According to data published by the International Energy Agency, global emissions of energy-related carbon dioxide $\left(\mathrm{CO}_{2}\right)$ reached 
32.3 billion tons in 2014. The IPCC Fifth Assessment Report (AR5) mentions, "Since the 20th century, global warming is primarily caused by human activities, which affect the climate mainly through greenhouse gas (GHG) emissions." The 2015 BP Statistical Review of World Energy showed that petroleum, coal, and natural gas are dominant fuels, accounting for $32.6 \%, 30.0 \%$, and $23.7 \%$ of global one-time energy consumption, respectively. The large-scale consumption of fossil energy, such as petroleum, coal, and natural gas, also emits abundant $\mathrm{CO}_{2}$, $\mathrm{N}_{2} \mathrm{O}$, and other GHGs, leading to global warming.

As the world's largest energy consumer and emitter of carbon emissions, China has been proactive in carbon emission management and control. Given that the levels of economic and social development differ markedly among China's provinces, the country should adopt a reasonable allocation of regional emission reduction targets through what is known as the "common but differentiated" principle. Although the central government has established emission reduction targets for the provinces, these targets are largely based on regional GDP output, which means that the more developed provinces are expected to attain stricter emission reduction targets. As a result, the more developed provinces may be reluctant to make additional efforts to reduce emissions, while the less developed western provinces face much less pressure.

In order to balance the rational use of natural resources and sustainable development, the central government has enhanced various resource regulations. During the 11th (2006-10) and $12^{\text {th }}$ Five-Year Plan periods, the intention was to reduce energy consumption per unit GDP by $20 \%$ and $16 \%$, respectively [7-8]. However, a lack of accountability for provincial emissions and energy reduction efforts has led to poor implementation of national policies; consequently, the central government has decided to place particular emphasis on the allocation of natural resources to the provinces and autonomous regions. The efforts by and cooperation of the provinces are essential elements in achieving the energy consumption targets of the government.

As a nonparametric efficiency assessment technique, data envelopment analysis (DEA) has become popular in environmental performance measurement [9-10]. In addition to the DEA model [11-16], researchers employ the traditional Charnes-Cooper-Rhodes (CCR) and BankerCharnes-Cooper (BCC) models, and various improved models to analyze energy or carbon efficiency in Chinese provinces [17-20] and the industrial sector [21-22]. Various researchers have also used the slack-based measurement (SBM) model and directional distance function (DDF) to measure carbon and energy efficiency in China [23-26]. As regards the influencing factors, currently the literature points to the influence of energy intensity on carbon intensity [27-28], as well as the influence of economic development and industrial structure [29].

Taking into account the specific circumstances of the various regions and, accordingly, rationally allocating carbon emission quotas are crucial to achieving lowcarbon development in the country. Therefore, it is necessary to evaluate scientifically the efficiency of regional carbon emissions and their development trend. In addition, factors such as the internal relations of emissions with the economic scale, industrial structure, environmental regulations, trade dependence, foreign capital dependence, technological innovation, and others have to be explored. It is most important to establish and perfect the national carbon emission market in China in order to carry out the initial allocation of regional carbon emission quotas reasonably and effectively. In view of the above, in this study we compared the carbon emission efficiency measured by the EBM-DEA model with that of the traditional CCR, BCC-DEA, and SBM models. In this paper, we divided the 30 provinces of China into eight economic regions and analyzed the differences in regional carbon emission efficiency. In addition, we established random effects panel data and used the Tobit-DEA model to analyze the relationship between various factors. These include economic growth, industrial structure, environmental regulation, trade dependence, dependence on foreign capital, technological innovation, and regional characteristics relevant to carbon emission efficiency and its influencing factors.

\section{Methods and Data}

The CCR model assumes that returns are constant and that they include technical efficiency as an integral part of economies of scale, often referred to as "integrated technical efficiencies" [30].

$$
\begin{aligned}
& \min \sum_{i=1}^{m} v_{i} x_{i k} \\
& \text { s.t. }\left\{\begin{array}{l}
\sum_{r=1}^{s} \mu_{r} y_{r j}-\sum_{i=1}^{m} v_{i} x_{i j} \leq 0 \\
\sum_{r=1}^{q} \mu_{r} y_{r k}=1 \\
v \geq 0 ; \mu \geq 0 \\
i=1,2, \ldots, m ; r=1,2, . ., q ; j=1,2, \ldots, n
\end{array}\right.
\end{aligned}
$$

In addition, the CCR model assumes that all the evaluated DMUs are at an optimal production scale stage, i.e., they are at a stage of constant returns to scale, assuming that the returns to scale of the production technology do not change, or the production technology scale returns are variable. However, in actual production many production units are not at an optimal scale of production, the CCR model of the technical efficiency of the inclusion of the scale of efficiency components. The BCC model is based on the variable returns to scale (VRS), and the resulting technical efficiency excludes the effect of scale, hence the term "purely technical efficiency" [31]. The outputoriented $\mathrm{BCC}$ model is: 
Table 1. Input and output variables descriptive statistics (2006-13).

\begin{tabular}{|c|c|c|c|c|c|}
\hline Variable & Unit & Mean & Standard & Minimum & Maximum \\
\hline Population & 10,000 persons & $4,350.84$ & $2,691.12$ & 285.00 & $10,594.00$ \\
\hline GDP & 100 million Yuan & $13,061.53$ & $11,049.55$ & 648.50 & $57,067.92$ \\
\hline K & 100 million Yuan & $6,566.73$ & $5,178.38$ & 491.90 & $26,570.80$ \\
\hline Energy consumption & 10,000 tons & $12,188.02$ & $7,797.70$ & 920.00 & $38,899.00$ \\
\hline Carbon emission & 10,000 tons & $31,297.52$ & $21,836.33$ & $2,345.00$ & $117,818.00$ \\
\hline
\end{tabular}

$\operatorname{Min} \varphi$
s.t. $\left\{\begin{array}{l}\sum_{j=1}^{n} \lambda_{j} x_{i j} \leq x_{i k} \\ \sum_{j=1}^{n} \lambda_{j} y_{r j} \geq \varphi y_{r k} \\ \sum_{j=1}^{n} \lambda_{j}=1 \\ \lambda>0 ; i=1,2, \ldots, m ; r=1,2, . ., q ; j=1,2, \ldots, n\end{array}\right.$

As regards the radial DEA model, the measurement of the inefficiency level contains only the proportion of the reduction (increase) in all inputs (outputs). For an invalid DMU, the gap between its current state and the strong target value includes, in addition to the proportionally improved portion, a portion of relaxation improvement. However, the relaxation of the improved part of the efficiency of the measurement value is not reflected. In this regard, Tone Kaoru (2001) proposed the slacks-based measure (SBM) model [32]:

Table 2. Variable descriptive statistics of influencing factors.

\begin{tabular}{|c|c|c|c|c|}
\hline Variable & Mean & Standard & Minimum & Maximum \\
\hline $\begin{array}{c}\text { EBM } \\
\text { efficiency } \\
\text { value }\end{array}$ & 0.8533 & 0.0758 & 0.7175 & 0.9571 \\
\hline Economic scale & 0.0328 & 0.0134 & 0.0157 & 0.0556 \\
\hline $\begin{array}{c}\text { Industrial } \\
\text { structure }\end{array}$ & 46.0503 & 6.9619 & 38.7688 & 59.7733 \\
\hline $\begin{array}{c}\text { Environmental } \\
\text { regulation }\end{array}$ & 177.6856 & 102.4330 & 40.5000 & 408.3200 \\
\hline $\begin{array}{c}\text { Trade } \\
\text { dependence }\end{array}$ & 0.3192 & 0.2793 & 0.0881 & 0.9238 \\
\hline $\begin{array}{c}\text { FDI } \\
\text { Technological } \\
\text { innovation }\end{array}$ & 0.0298 & 0.0118 & 0.0107 & 0.0525 \\
\hline $\begin{array}{c}\text { Regional } \\
\text { characteristics }\end{array}$ & 383.8782 & 294.6819 & 129.8273 & 965.7538 \\
\hline
\end{tabular}

$$
\begin{gathered}
\min \rho=\frac{1-\frac{1}{m} \sum_{i=1}^{m} s_{i}^{-} / x_{i k}}{1+\frac{1}{q} \sum_{i=1}^{q} s_{i}^{+} / y_{r k}} \\
\text { s.t. }\left\{\begin{array}{l}
X \lambda+s^{-}=x_{k} \\
Y \lambda-s^{+}=y_{k} \\
\lambda, s^{-}, s^{+} \geq 0
\end{array}\right.
\end{gathered}
$$

In order to solve the problems of the CRS and SBM models effectively, Tone (2010) constructed an integrated EBM model with radial and non-radial characteristics [33]. For $\mathrm{n}$ decision-making units, with $\mathrm{m}$ inputs $(\mathrm{x})$ and $\mathrm{s}$ outputs (y), the EBM model can be expressed as:

$$
\begin{gathered}
\gamma^{*}=\min _{\theta, \lambda, s^{-}} \theta-\varepsilon_{x} \sum_{i=1}^{m} \frac{w_{i}^{-} s_{i}^{-}}{x_{i 0}} \\
\text { s.t. }\left\{\begin{array}{l}
\theta x_{0}-X \lambda-s^{-}=0 \\
\lambda Y \geq y_{0}, \lambda \geq 0, s^{-} \geq 0
\end{array}\right.
\end{gathered}
$$

The Tobit model is an econometric model for the dependent variable of partial continuous distribution and partial discrete distribution [34]. If $Y_{i}^{*}$ were truncated data between 0 and 1 , and $Y_{i}^{*}$ were related to the regression factor, then the linear regression model would be:

$$
Y_{i}^{*}=\beta_{0}+\beta_{1} x_{i}+\mu_{i}
$$

...where $\mathrm{i}=1,2, \ldots, \mathrm{n}$. When estimating using the observed alternatives, the resulting OLS estimates are inconsistent. Therefore, the Tobit model deduces the corresponding likelihood function by making obey the additional assumption of normal distribution.

The carbon-emission quota efficiency value is between 0 and 1 and is a typical restricted dependent variable. Therefore, this paper uses the DEA-Tobit model to examine the relationship between the efficiency of the carbon emission quota and its influencing factors. The model is: 
Table 3. Regional EBM efficiency (2006-13).

\begin{tabular}{|c|c|c|c|c|c|c|c|c|c|c|}
\hline Province & 2006 & 2007 & 2008 & 2009 & 2010 & 2011 & 2012 & 2013 & Mean & Rank \\
\hline Anhui & 0.773 & 0.710 & 0.692 & 0.724 & 0.730 & 0.739 & 0.711 & 0.706 & 0.723 & 25 \\
\hline Beijing & 1.000 & 1.000 & 1.000 & 1.000 & 1.000 & 1.000 & 1.000 & 1.000 & 1.000 & 1 \\
\hline Fujian & 0.860 & 0.853 & 0.828 & 0.861 & 0.871 & 0.892 & 0.914 & 0.914 & 0.874 & 15 \\
\hline Gansu & 0.796 & 0.815 & 0.785 & 0.795 & 0.779 & 0.787 & 0.773 & 0.756 & 0.786 & 20 \\
\hline Guangdong & 1.000 & 1.000 & 1.000 & 1.000 & 1.000 & 1.000 & 1.000 & 1.000 & 1.000 & 1 \\
\hline Guangxi & 0.727 & 0.733 & 0.713 & 0.681 & 0.696 & 0.718 & 0.721 & 0.723 & 0.714 & 26 \\
\hline Guizhou & 0.728 & 0.742 & 0.724 & 0.778 & 0.757 & 0.762 & 0.781 & 0.810 & 0.760 & 22 \\
\hline Hainan & 0.845 & 1.000 & 1.000 & 1.000 & 1.000 & 1.000 & 1.000 & 1.000 & 0.981 & 6 \\
\hline Hebei & 0.813 & 0.828 & 0.827 & 0.832 & 0.790 & 0.845 & 0.835 & 0.809 & 0.822 & 17 \\
\hline Henan & 0.818 & 0.813 & 0.786 & 0.766 & 0.743 & 0.736 & 0.724 & 0.716 & 0.763 & 23 \\
\hline Heilongjiang & 1.000 & 1.000 & 1.000 & 1.000 & 0.930 & 1.000 & 1.000 & 0.938 & 0.983 & 8 \\
\hline Hubei & 0.737 & 0.756 & 0.757 & 0.774 & 0.761 & 0.811 & 0.821 & 0.835 & 0.781 & 19 \\
\hline Hunan & 0.758 & 0.783 & 0.790 & 0.776 & 0.757 & 0.805 & 0.818 & 0.833 & 0.790 & 18 \\
\hline Jilin & 0.871 & 0.818 & 0.729 & 0.763 & 0.774 & 0.742 & 0.737 & 0.755 & 0.774 & 21 \\
\hline Jiangsu & 0.879 & 0.882 & 0.879 & 0.881 & 0.908 & 0.905 & 0.911 & 0.894 & 0.893 & 12 \\
\hline Jiangxi & 0.788 & 0.762 & 0.737 & 0.728 & 0.766 & 0.747 & 0.736 & 0.697 & 0.745 & 24 \\
\hline Liaoning & 1.000 & 1.000 & 0.924 & 1.000 & 1.000 & 1.000 & 1.000 & 0.989 & 0.989 & 5 \\
\hline InnerMongolia & 0.795 & 0.836 & 0.900 & 1.000 & 1.000 & 1.000 & 1.000 & 1.000 & 0.941 & 9 \\
\hline Ningxia & 0.665 & 0.721 & 0.789 & 0.896 & 1.000 & 1.000 & 1.000 & 1.000 & 0.884 & 11 \\
\hline Qinghai & 0.468 & 0.510 & 0.583 & 0.585 & 0.589 & 0.632 & 0.659 & 0.664 & 0.586 & 30 \\
\hline Shandong & 0.828 & 0.848 & 0.852 & 0.895 & 0.902 & 0.900 & 0.900 & 0.929 & 0.882 & 14 \\
\hline Shanxi & 1.000 & 1.000 & 1.000 & 1.000 & 1.000 & 1.000 & 1.000 & 1.000 & 1.000 & 4 \\
\hline Shaanxi & 1.000 & 1.000 & 1.000 & 0.869 & 0.908 & 0.893 & 0.886 & 0.885 & 0.930 & 10 \\
\hline Shanghai & 1.000 & 1.000 & 1.000 & 1.000 & 1.000 & 1.000 & 1.000 & 0.989 & 0.999 & 3 \\
\hline Sichuan & 0.636 & 0.638 & 0.641 & 0.628 & 0.604 & 0.652 & 0.668 & 0.674 & 0.643 & 28 \\
\hline Tianjin & 0.973 & 0.960 & 0.959 & 0.945 & 1.000 & 1.000 & 1.000 & 1.000 & 0.980 & 7 \\
\hline Xinjiang & 0.789 & 0.794 & 0.792 & 0.890 & 0.924 & 0.900 & 0.908 & 0.932 & 0.866 & 16 \\
\hline Yunnan & 0.728 & 0.696 & 0.680 & 0.702 & 0.681 & 0.680 & 0.679 & 0.695 & 0.692 & 27 \\
\hline Zhejiang & 0.890 & 0.898 & 0.869 & 0.902 & 0.925 & 0.904 & 0.902 & 0.866 & 0.895 & 13 \\
\hline Chongqing & 0.561 & 0.559 & 0.588 & 0.591 & 0.591 & 0.632 & 0.658 & 0.690 & 0.609 & 29 \\
\hline
\end{tabular}

$$
\begin{aligned}
E_{i t}= & \alpha_{i}+\beta_{1} E S_{i t}+\beta_{2} I S_{i t}+\beta_{3} \ln E R_{i t}+\beta_{4} \text { Trade }_{i t} \\
& +\beta_{5} F D I_{i t}+\beta_{6} \text { Tech }_{i t}+\beta_{7} \ln \text { Pop }_{i t}+\varepsilon_{i t}
\end{aligned}
$$

...where $i$ is the region and $\mathrm{t}$ is the year. $E$ is the efficiency value, $E S$ is the economic scale, $I S$ is the industrial structure, ER is environmental regulation, Trade is trade dependence, FDI is the dependence on foreign capital, Tech is technical innovation, and Pop is population density. The parameter to be estimated is $\beta$ and $\varepsilon$ is the error term.
We selected 2006-13 as the research period because of the availability of data, and we used the 30 provinces in China as the research object (this study does not include Tibet, Hong Kong, Macao, and Taiwan owing to a lack of relevant data). The input variables are:

1. The number of employed persons by region, which is the number of employees at the end of a calendar year.

2. Capital stock, the $\mathrm{K}$ value is calculated by using the Goldsmith (1951) perpetual inventory method [35].

3. Energy consumption is the total regional energy consumption; the output variables are GDP and carbon emission. 
As regards GDP, a deflator was used to convert to the 2000 constant prices, eliminating the impact of price changes. Energy consumption was multiplied by the corresponding carbon intensity factor. The data were obtained from the China Statistical Yearbook,
China Energy Statistical Yearbook, Chi'a's Foreign Trade Statistics Yearbook, and the Statistical Yearbook of the Provinces over the years. The descriptive statistics of the input and output variables are shown in Table 1.

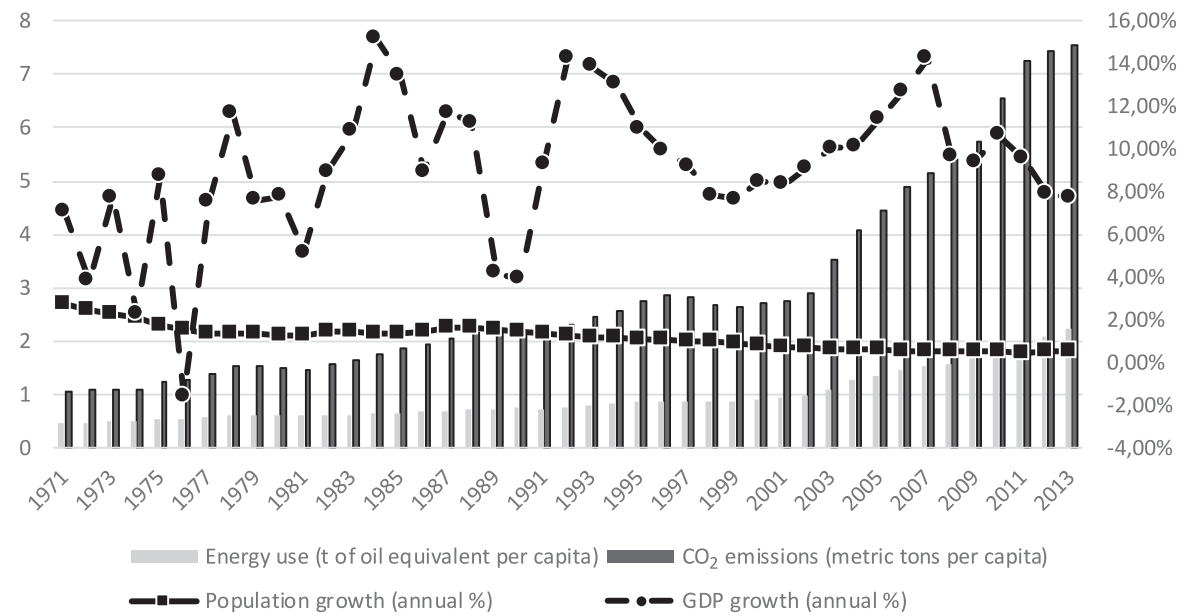

Fig. 1. China's GDP growth, Population growth, Energy consumption and $\mathrm{CO}_{2}$ emissions.

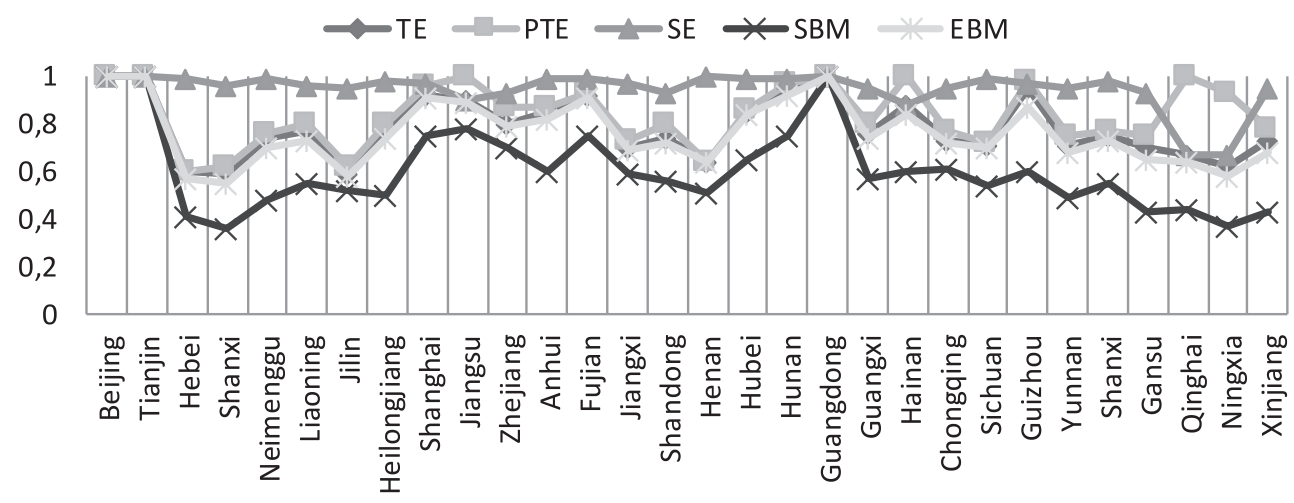

Fig. 2. Mean value of regional carbon emission efficiency.

TE: technical efficiency, PTE: pure technical efficiency, SE: scale efficiency, SBM: slacksbased measure, EBM: epsilon-based measure.

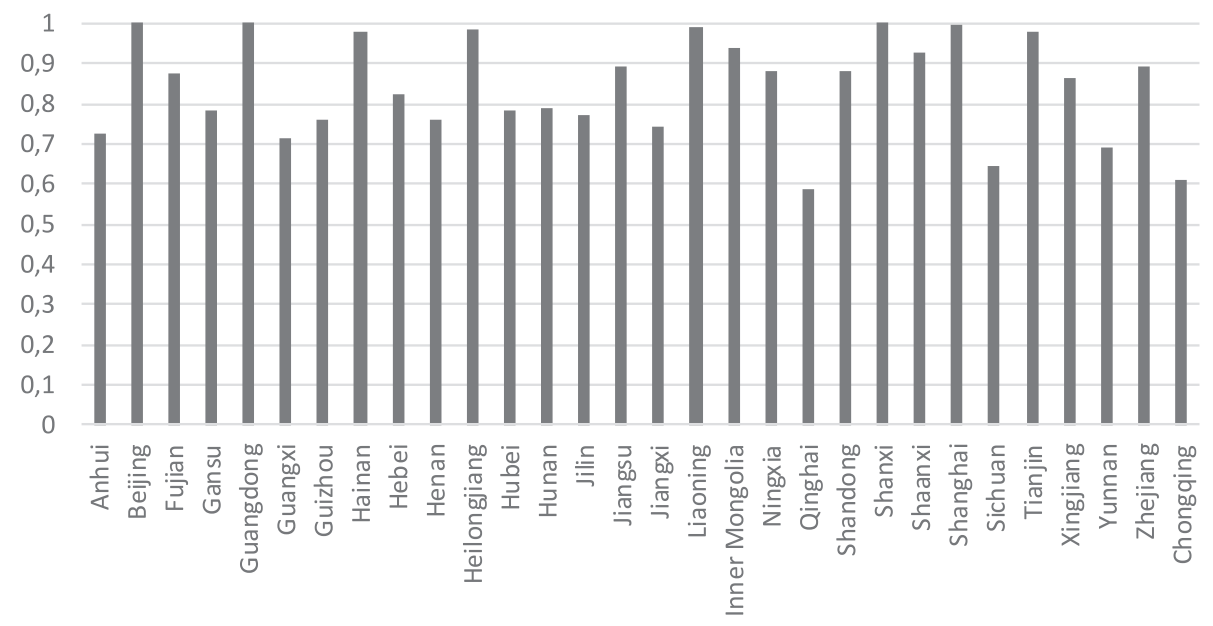

Fig. 3. Regional EBM efficiency average for 2006-2013. 


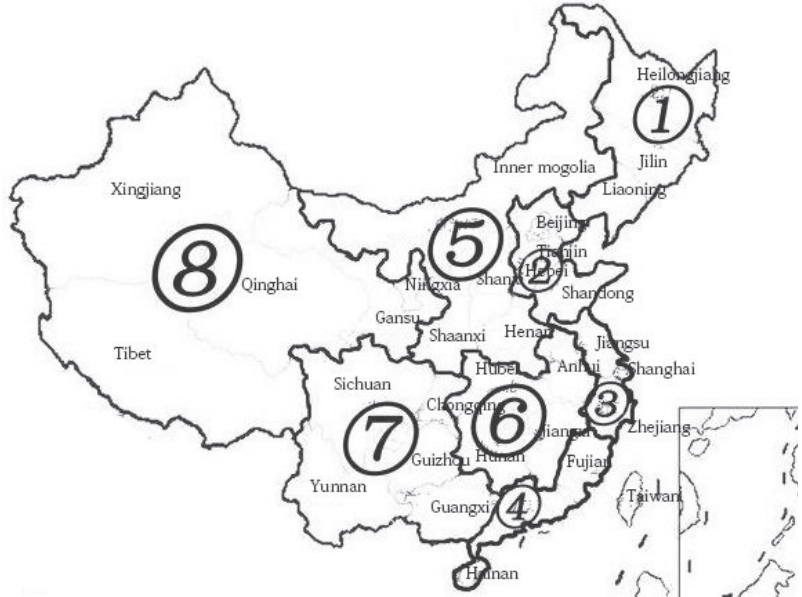

Fig. 4. Map of China and the eight economical regions

a)

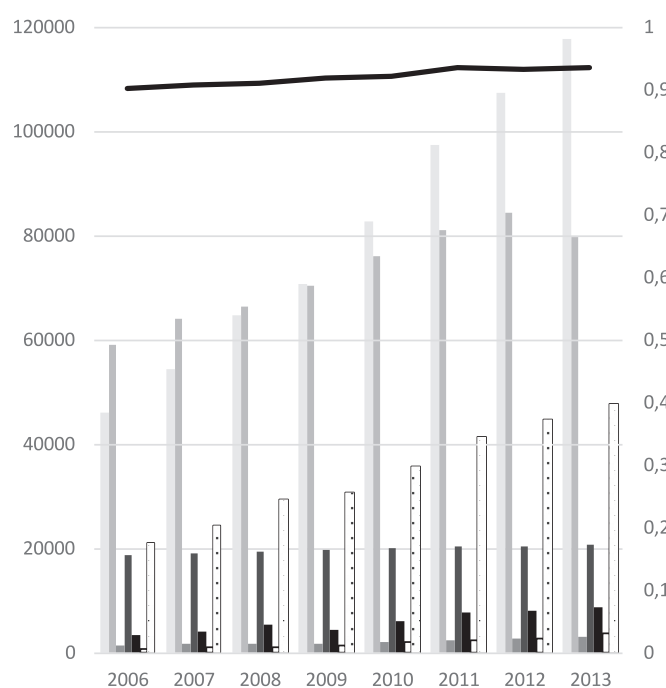

c)
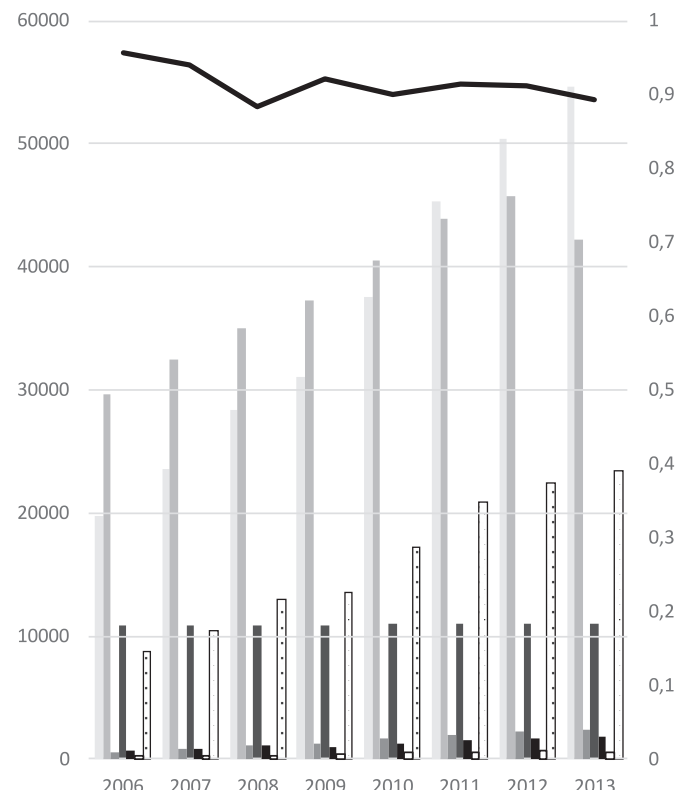

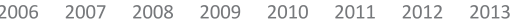

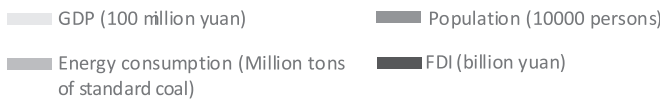

As influencing factor variables we selected:

1. Economic scale (the gross regional product as a percentage of the gross domestic product).

2. Industrial structure (the ratio of industrial added value to the local GDP).

3. Environmental regulations (income from pollution by region).

4. Trade dependence (import and export trade as a percentage of GDP).

5. Dependence on foreign investment (the proportion of foreign investment in the GDP in each province).

6. Technological innovation (research and development expenditure as a percentage of GDP.

7. Regional characteristics (population density [Pop]).

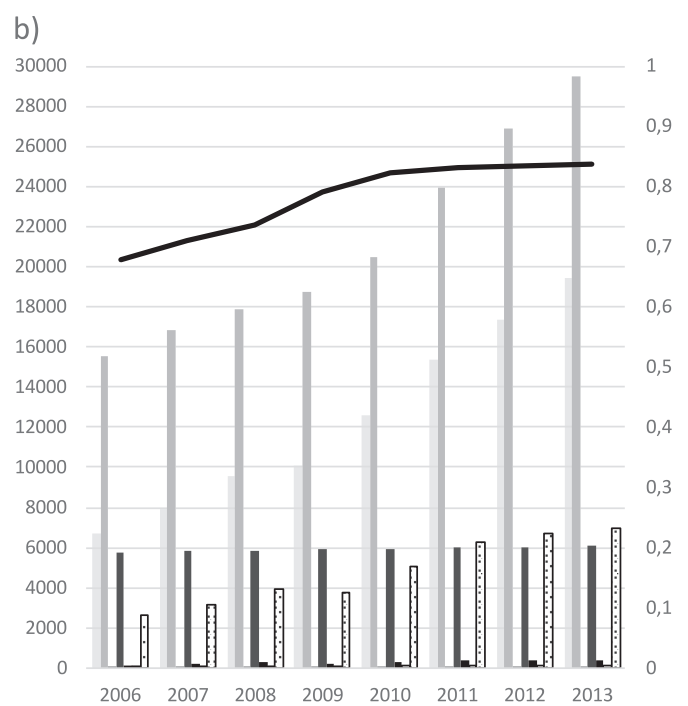

d)

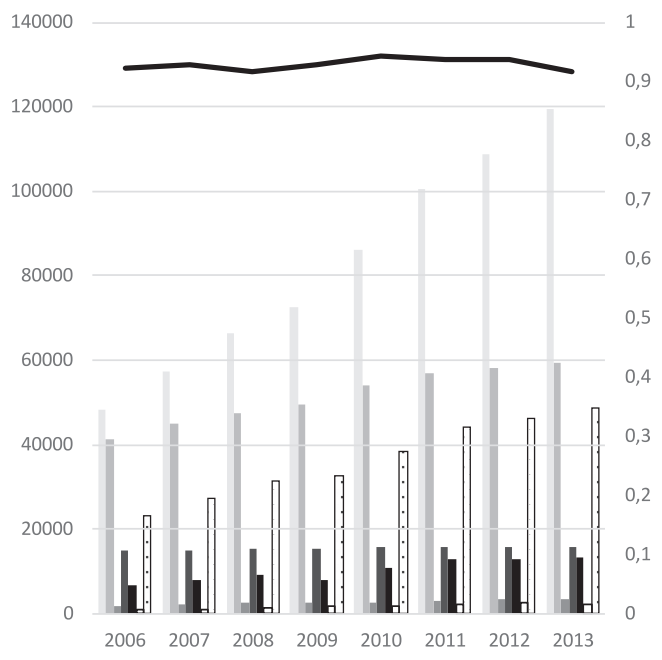

$\begin{array}{llllllll}2006 & 2007 & 2008 & 2009 & 2010 & 2011 & 2012 & 2013\end{array}$

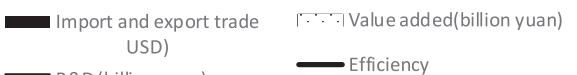

$\square R \& D$ (billion yuan) $\quad$ Efficiency 

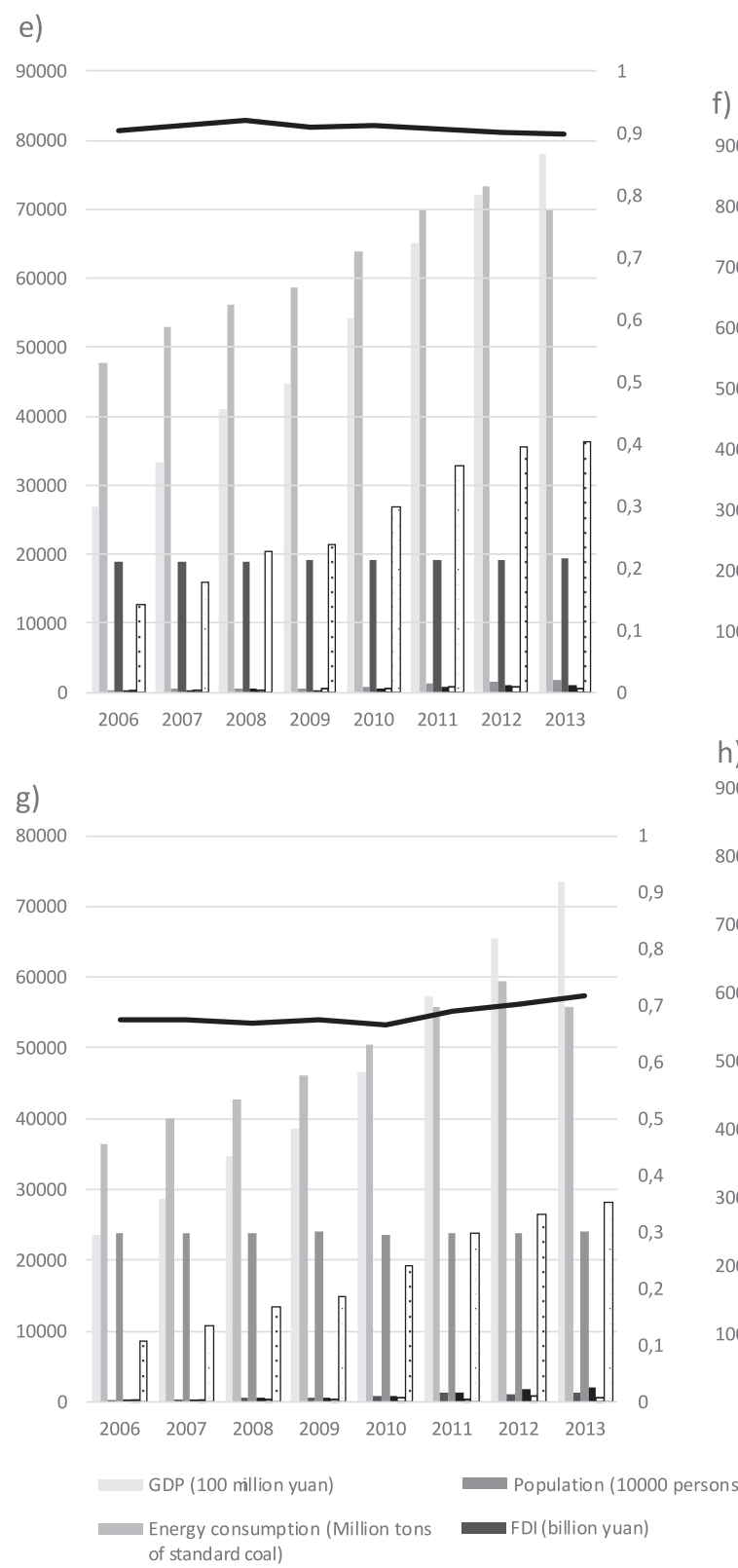

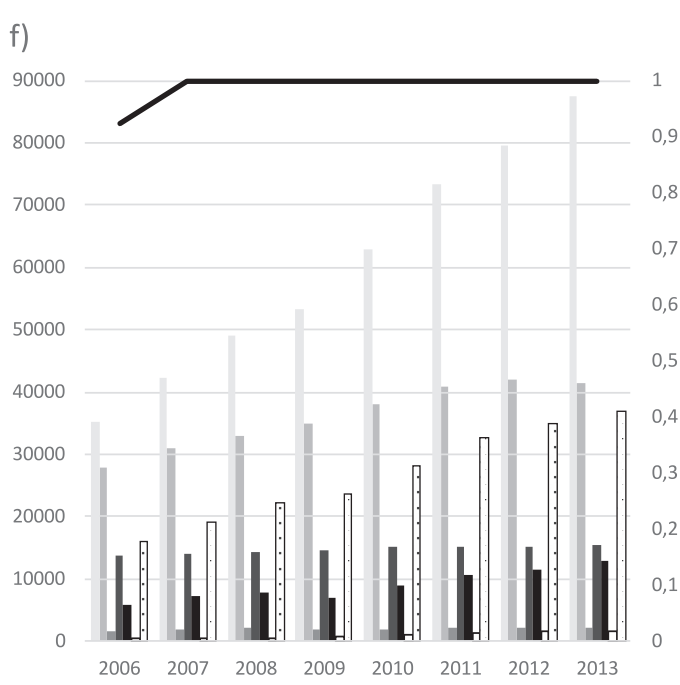

h)
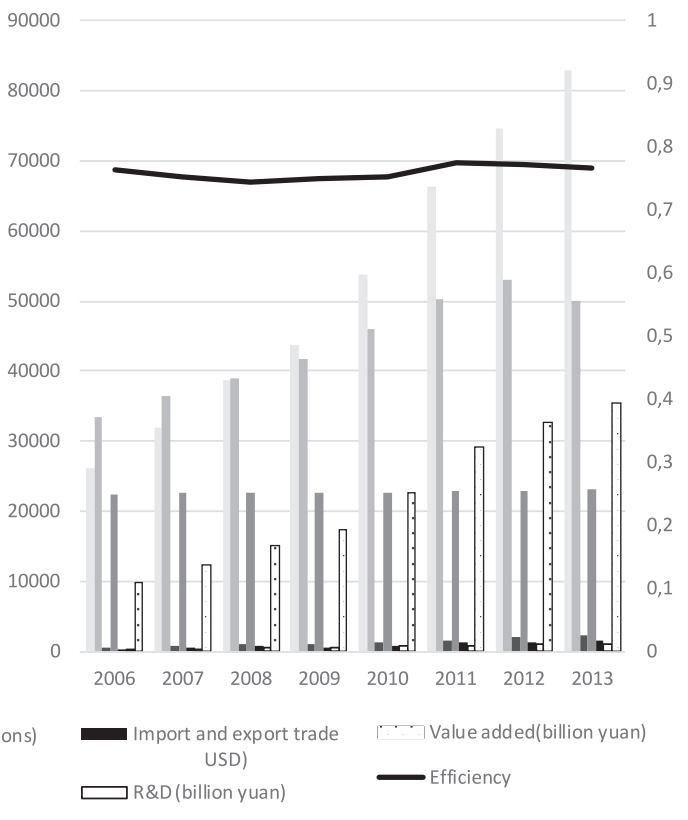

Fig. 5.The efficiency trends and Factors in the eight major integrated economic zones, 2006-2013: a) Northern coastal economic zone (Northern), b) The Northwest Economic Zone, c) Northeast Comprehensive Economic Zone (Northeast), d) Eastern Coastal Economic Zone (Eastern), e) The middle reaches of the Yellow River Economic Zone (Yellow), f) Southern Coastal Economic Zone (Southern), g) The Southwest Economic Zone (Southwest), h) The middle reches of the Yangtze River Economic Zone (Yangtze).

EBM efficiency values were calculate by MaxDEA5.0 software. The other data were obtained from the China Statistical Yearbook, China Energy Statistical Yearbook, China's Foreign Trade Statistics Yearbook, and the Statistical Yearbook of the Provinces over the years. The descriptive statistics of each influencing factor are listed in Table 2.

\section{Results and Discussion}

We used the EBM-DEA model to analyze the input and output panel data of the provinces and cities of China for 2006-13. The descriptive statistics of the input-output variables are shown in Table 2. The regional efficiency values per calendar year were calculated, with the average efficiency of the cities for the period 2006-13, as shown in Fig. 2.

In the study, we first used the CCR and BCC models, with the CCR model being the constant returns to scale and the $\mathrm{BCC}$ model being the variable scale compensation. We calculated and analyzed the carbon emission efficiency from these two angles. The TE of each region was lower than were the PTE and SE, with Beijing, Tianjin, and Guangdong achieving a carbon efficiency value of 1 . These regions have high carbon emission efficiency and a rational allocation of resources, whereas Hebei, Shanxi, and Jilin have the lowest carbon emission efficiency, 
Table 4. DEA-Tobit panel data estimation results.

\begin{tabular}{|c|c|c|c|c|c|c|c|}
\hline Var & I & II & III & IV & V & VI & VII \\
\hline & $0.7218 * * *$ & $0.4494 * * *$ & $0.3944 * * *$ & $0.3905^{* * *}$ & $0.3906^{* * *}$ & $0.4549 * * *$ & $0.9733 * * *$ \\
\hline & $(-0.025)$ & $(0.0502)$ & $(0.0688)$ & $(0.0601)$ & $(0.0602)$ & $(0.0500)$ & $(0.1750)$ \\
\hline \multirow[t]{2}{*}{ ES } & $4.0019 * * *$ & $4.4811 * * *$ & $4.0696^{* * *}$ & $0.6693^{* *}$ & $0.6110^{*}$ & $-6.1101 * * *$ & $3.4679 * *$ \\
\hline & $(-0.75)$ & (0.4999) & $(0.6079)$ & (1.1954) & (2.2900) & (2.3874) & $(3.7682)$ \\
\hline \multirow[t]{2}{*}{ IS } & & $0.0056^{* * *}$ & $0.0055^{* * *}$ & $0.0062 * * *$ & $0.0062 * * *$ & $0.0045^{* * *}$ & $0.0026 * * *$ \\
\hline & & $(0.0010)$ & $(0.0009)$ & $(0.0009)$ & $(0.0011)$ & $(0.0010)$ & $(0.0011)$ \\
\hline \multirow[t]{2}{*}{$\ln E R$} & & & 0.0148 & 0.0202 & 0.0205 & 0.0039 & -0.0056 \\
\hline & & & $(0.0129)$ & $(0.0114)$ & $(0.0140)$ & -0.0117 & $(0.0108)$ \\
\hline \multirow[t]{2}{*}{ Trade } & & & & $0.1730 * * *$ & $0.1739 * * *$ & $0.1217 * * *$ & $0.0239 *$ \\
\hline & & & & $(0.0545)$ & $(0.0620)$ & $(0.0506)$ & $(0.0651)$ \\
\hline \multirow[t]{2}{*}{ FDI } & & & & & $0.0440 *$ & $3.9380 * * *$ & $2.3786^{* *}$ \\
\hline & & & & & $(1.4745)$ & (1.4743) & $(1.3931)$ \\
\hline \multirow[t]{2}{*}{ Tech } & & & & & & $16.6539 * * *$ & $16.5919 * * *$ \\
\hline & & & & & & $(3.8373)$ & (3.3749) \\
\hline \multirow[t]{2}{*}{$\operatorname{lnPop}$} & & & & & & & $-0.1064 * * *$ \\
\hline & & & & & & & $(0.0347)$ \\
\hline
\end{tabular}

Note: $* * *$, and $* * *$ denote significance levels at $10 \%, 5 \%$, and $1 \%$, respectively.

which needs to be adjusted. As regards PTE, the value for Beijing, Tianjin, and various other places was 1, indicating a relatively high level relevant to technology and management and the effective use of resources. The scale efficiency was relatively high, except for Qinghai and Ningxia; however, only Beijing and Tianjin achieved the highest scale efficiency.

Subsequently, we used the SBM model for undesirable outputs, as carbon emission efficiency is not a purely DEA problem and unintended output has to be taken into account. The SBM model considers non-expected output, and the calculated efficiency value is more suitable for objective conditions. As the calculation results in Fig. 1 show, the SBM efficiency value for each region was the lowest of all the values. The efficiency value for Beijing, Tianjin, and Guangdong was 1, whereas that for Hebei, Shanxi, Qinghai, Ningxia, and Xinjiang was the lowest at approximately 0.4 . This indicates that the efficiency of the carbon emissions allocation in these cities needs improvement.

Finally, we used the EBM model to combine the radial and non-radial characteristics, which could solve effectively the errors of the CCR, BCC, and SBM models, as the efficiency of the EBM model is more accurate. Fig. 2 shows that the EBM efficiency value of Beijing, Tianjin, and Guangdong is 1, whereas that of Shanxi, Ningxia, and Jilin is the lowest, indicating that carbon emission efficiency needs to be improved.

In particular, Fig. 3 shows the higher efficiency values (1.000, 1.000, 1.000, and 0.999, respectively) of Beijing,
Guangdong, Shanxi, Shanghai, and others. The areas with lower efficiency values are Qinghai, Chongqing, Sichuan, and Yunnan $(0.586,0.609,0.643$, and 0.692 , respectively) and others.

A report issued by the State Council Development Research Center indicates that "China following the Eastern, Central, and Western regional division method is outdated." In view of this statement, we propose a division into four plates, namely, eastern, central, western, and northeastern, with the four plates being divided into eight integrated economic zones of the specific concept of regional division. The eight economic zones (Fig. 4) are:

1. Northeast Comprehensive Economic Zone (Northeast), including Liaoning, Jilin, and Heilongjiang.

2. Northern coastal economic zone (Northern), including Beijing, Tianjin, Hebei, and Shandong.

3. Eastern coastal economic zone (Eastern), including Shanghai, Jiangsu, and Zhejiang .

4. Southern coastal economic zone (Southern), including Fujian, Guangdong, and Hainan.

5. The middle reaches of the Yellow River Economic Zone (Yellow), including Shaanxi, Shanxi, Henan, and Inner Mongolia.

6. The idle reaches of the Yangtze River Economic Zone (Yangtze), including Hubei, Hunan, Jiangxi, and Anhui.

7. The Southwest Economic Zone (Southwest), including Yunnan, Guizhou, Sichuan, Chongqing, and Guangxi.

8. The Northwest Economic Zone (Northwest), including Gansu, Qinghai, Ningxia, and Xinjiang. 
As can be seen from Fig. 5, the overall national efficiency value remained above 0.8 , with a steady upward trend. The efficiency value of the southern coastal economic zone is above 0.9 and rises steadily year by year. This zone is the most important export-oriented economic development base in the southern coastal economic region of the country. The zone is the base for digesting foreign advanced technology, and, as it faces the rich Hong Kong-Macao resources, it has a high degree of opening up to the outside world. The Northeast Comprehensive Economic Zone had the highest efficiency value in 2006, but in recent years this has shown a downward trend. The downward trend was caused by the various challenges that the natural conditions and resources endowment structure is currently facing, such as resource depletion, the industrial structure needing to be upgraded, and the like. The northern coastal economic zone is the most powerful high-technology research and development and manufacturing center and maintains an efficiency level of 0.9 or more, with slight increases year after year. Various factors, such as the geographical location of this region, convenient transportation, science and technology education, and cultural activities have led to remarkable achievements. The efficiency of the eastern coastal economic zone remained at 0.9 or above, but the overall trend has declined. This area has a close connection with foreign economy, modernized early start, abundant human resources, and less opportunity for efficiency improvement. The economic efficiency of the middle reaches of the Yellow River is about 0.9, decreasing slightly in recent years. The decline, despite an abundance of natural resources, especially coal and natural gas, is ascribed to the lack of opening up to the outside world, which makes the task of structural adjustment difficult. The economic efficiency of the middle reaches of the Yangtze River is approximately 0.75 , which is attributed to the denseness of the region, the low level of opening up to the outside world, and the specialized production bases of rice and cotton and related processing industries, and iron and nonferrous metallurgy. However, in recent years, the western development strategy policy of China has been favorable to the development of the region because of the poor natural conditions, sparsely populated areas, and narrow market. In addition, the economic efficiency of the western region is relatively low, but the overall efficiency value is on the rise. The Southwest Economic Zone has the lowest efficiency value because of the geographical location, remote and barren land, and the poverty of the population; consequently, the original mode of economic production needs to be improved.

The regional differences in efficiency value are closely related to the level of economic development, industrial structure, technology level, and openness of trade in these regions. Therefore, based on the EBM measurement efficiency, this study employed the Tobit model for further testing of each influencing variable, using the measurement software Stata13.0. The descriptive statistics of the influencing variables are shown in Table 2. We used the random-effect panel Tobit model estimation results as shown in Table 4.

The Tobit panel data estimation results show that:

1. The economic scale of carbon emission efficiency is positive and extremely significant. This indicates that with the expansion of economic scale there will be improvements in the changing production mode, total amount of carbon emission control in the premise, government rational allocation of carbon emission quotas, and the relative efficiency of quota allocation.

2. Improvement of the industrial structure is conducive to the improvement of quota allocation efficiency. This is because the industrial carbon emissions in China account for more than $70 \%$ of the total carbon emissions of the country. Therefore, optimizing the industrial structure and actively developing the tertiary industry will contribute to the improvement of carbon emission efficiency.

3. The effect of environmental regulations on the efficiency of quota allocation is not significant. This is because the increase of pollution charges cannot effectively reduce carbon emissions; therefore, the role of the carbon-trading market needs to be developed fully.

4. The effect of trade dependence on the efficiency of quota allocation is significant and positive, indicating that with the increase in the proportion of import and export trade in the GDP, it is conducive to the transfer of carbon emissions and will improve the efficiency of carbon emissions.

5. The increase in foreign capital dependence will be conducive to the improvement of carbon emission efficiency, as the increase in foreign direct investment, advanced technology management, and the spillover effects will be beneficial to the reduction of carbon emissions.

6. Technological innovation is conducive to improving the efficiency of carbon emissions, the increase in research and development investment is conducive to the improvement of science and technology, and science and technology progress is conducive to carbon intensity reduction.

7. The relationship between regional characteristics and carbon emission efficiency is negative and significant, which indicates that the increase in population density improves carbon emissions and is not conducive to the improvement of carbon emission efficiency.

\section{Conclusions}

In this study we used the CCR, BCC, SBM, and EBMDEA models to study regional carbon emission efficiency in China. We found that the EBM-DEA model could solve the efficiency errors of the CCR, BCC, and SBM models at the same time. In addition, the EBM efficiency measurements could be more accurate because of the integrated radial and non-radial characteristics. Significant differences were found in the measured regional carbonemission efficiency values of China. 
Based on EBM-DEA carbon emission efficiency, we divided the local regions into eight economic zones. Significant differences were found among these regions that are attributable to such factors as economic scale, openness, population density, and technical level.

The Tobit model was used for analysis in order to explore the factors that influence the differences in regional carbon-emission efficiencies. The results show that economic scale, industrial structure, dependence on foreign trade and foreign capital, and technological innovation have positive effects on carbon emission efficiency. Environmental regulation has no significant effect on carbon emission efficiency, and regional characteristics have negative effects on carbon emission efficiency.

The results indicate that as regards the carbon emissions of China relevant to the establishment of a unified national market, the government has to consider various factors. These include conducting scientific evaluation of the regional carbon emission efficiency of the country and its development trend, taking into account the regional economies of scale, industrial structure, trade dependence, foreign dependence, technological innovation, and various other factors. In addition, various other factors have to be considered, such as reasonably determining the regional emission reduction targets, effectively allocating regional carbon emission initial quota, and establishing and improving the carbon emissions trading system.

\section{Acknowledgements}

This study was supported by the National Natural Science Foundation of China (grant No. 71673022) and the National Natural Science Foundation of China (grant No. 71272160).

\section{References}

1. ZHANG W., YANG S. The influence of energy consumption of China on its real GDP from aggregated and disaggregated viewpoints. Energy Policy. 57, 76, 2013.

2. WU H., SHI Y., XIA Q., ZHU W.D. Effectiveness of the policy of circular economy in China: A DEA-based analysis for the period of 11th five-year-plan. Resour. Conserv. \& Recycl. 83, 163, 2014.

3. SONG M., ZHANG L., AN Q., WANG Z., LI Z. Statistical analysis and combination forecasting of environmental efficiency and its influential factors since China entered the WTO: 2002-2010-2012. J. Clean. Prod. 42, 42, 2013.

4. WANG K., YU S., ZHANG W. China's regional energy and environmental efficiency: A DEA window analysis based dynamic evaluation. Math. Comp. Model. 58, 1117, 2013

5. WU J., XIONG B., AN Q., ZHU Q., LIANG L. Measuring the performance of thermal power firms in China via fuzzy Enhanced Russell measure model with undesirable outputs. J. Clean. Prod. 102, 237, 2015.

6. WU J., AN Q., YAO X., WANG B. Environmental efficiency evaluation of industry in China based on a new fixed sum undesirable output data envelopment analysis. J. Clean. Prod. 74, 96, 2014.
7. WANG K., ZHANG X., WEI Y.M., YU S. Regional allocation of $\mathrm{CO}_{2}$ emissions allowance over provinces in China by 2020. Energy Policy. 54, 214, 2013.

8. ZHANG B., BI J., FAN Z., YUAN Z., GE J. Eco-efficiency analysis of industrial system in China: a data envelopment analysis approach. Ecol. Econ. 68, 306, 2008.

9. LI L.B., HU J.L. Ecological total-factor energy efficiency of regions in China. Energy Policy. 46, 216, 2012.

10. ZHOU P., ANG B.W., POH K.L. A survey of data envelopment analysis in energy and environmental studies. Eur. J. Oper. Res. 189, 1, 2008.

11. ZHOU P., POH K.L., ANG B.W. A non-radial DEA approach to measuring environmental performance. Eur. J. Oper. Res. 178, 1, 2007.

12. ZHOU P., ANG B.W., POH K.L. Measuring environmental performance under different environmental DEA technologies. Energy Econ. 30, 1, 2008.

13. FEI R., LIN B. Energy efficiency and production technology heterogeneity in China's agricultural sector: A meta-frontier approach. Technol. Forecast. Soc. 109, 25, 2016.

14. WANG Q., ZHOU P., ZHOU D. Efficiency measurement with carbon dioxide emissions: the case of China. Appl. Energy. 90, 161, 2012.

15. WANG Z., FENG C., ZHANG B. An empirical analysis of China's energy efficiency from both static and dynamic perspectives. Energy. 74, 322, 2014.

16. BIAN Y., YANG F. Resource and environment efficiency analysis of provinces in China: A DEA approach based on Shannon's entropy. Energy Policy. 38, 1909, 2010.

17. WANG K., LU B., WEI Y.M. China's regional energy and environmental efficiency: a range-adjusted measure based analysis. Appl. Energy. 112, 1403, 2013.

18. WANG K., WEI Y.M., ZHANG X. A comparative analysis of China's regional energy and emission performance: Which is the better way to deal with undesirable outputs? Energy Policy. 46, 574, 2012.

19. LI K., LIN B. The improvement gap in energy intensity: Analysis of China's thirty provincial regions using the improved DEA (data envelopment analysis) model. Energy. 84, 589, 2015.

20. SHI G.M., BI J., WANG J.N. Chinese regional industrial energy efficiency evaluation based on a DEA model of fixing non-energy inputs. Energy policy. 38, 6172, 2010.

21. XIAOLI Z., RUI Y., QIAN M. China's total factor energy efficiency of provincial industrial sectors. Energy. 65, 52, 2014.

22. CHOI Y., ZHANG N., ZHOU P. Efficiency and abatement costs of energy-related $\mathrm{CO}_{2}$ emissions in China: a slacksbased efficiency measure. Appl. Energy. 98, 198, 2012.

23. ZHANG N., CHOI Y. Environmental energy efficiency of China's regional economies: a non-oriented slacks-based measure analysis. Social Sci. J. 50, 225, 2013.

24. ZHOU P., ANG B.W., POH K.L. Slacks-based efficiency measures for modeling environmental performance. Ecol. Econ. 60, 111, 2006.

25. CHIU Y.H., LIN J.C., HSU C.C., WL JIA. Carbon emission allowances of efficiency analysis: application of super SBM ZSG-DEA model. Pol J Environ Stud. 22, 653, 2013.

26. CHEN L., LIU J., WANG X., ZHANG Z. Marginal Carbon Abatement Cost Estimation Based on the DDF Dynamic Analysis Model - Taking Tianjin for Example. Systems Eng. 9, 11, 2014.

27. XU S.C., HE Z.X., LONG R.Y. Factors that influence carbon emissions due to energy consumption in China: Decomposition analysis using LMDI. Appl. Energy. 127, 182, 2014. 
28. JIN J., ZHOU D., ZHOU P. Measuring environmental performance with stochastic environmental DEA: the case of APEC economies. Econ. Model. 38, 80, 2014.

29. FODHA M., ZAGHDOUD O. Economic growth and pollutant emissions in Tunisia: an empirical analysis of the environmental Kuznets curve. Energy Policy. 38, 1150, 2010.

30. CHARNES A., COOPER W.W., RHODES E. Measuring the efficiency of decision making units. Eur. J. Oper. Res. 2, 429, 1978.

31. BANKER R.D., CHARNES A., COOPER W.W. Some models for estimating technical and scale inefficiencies in data envelopment analysis. Manage. Sci. 30, 1078, 1984.
32. TONE K. A slacks-based measure of efficiency in data envelopment analysis. Eur. J. Oper. Res. 130, 498, 2001.

33. TONE K., TSUTSUI M. An epsilon-based measure of efficiency in DEA-A third pole of technical efficiency. Eur. J. Oper. Res. 207, 1554, 2010.

34. GOLDSMITH R.W. A perpetual inventory of national wealth. National Bureau of Economic Research, Inc, 1951.

35. KIRJAVAINEN T., LOIKKANENT H.A. Efficiency differences of Finnish senior secondary schools: an application of DEA and Tobit analysis. Econ. Education Review. 17, 377, 1998. 